340 Case of change of colour in the North American Indian. [Oct.

Case of change of colour in the North American Indian. By Dr. Emery Bissell.

[Communicated for the New-England Journal of Medicine and Surgery.]

7 THE subject of this singular phenomenon was Samuel Adams, one of the tribe of Brothertown Indians, living in this vicinity. I saw him in the winter of 1816. - The colour of his skin at that time had undergone an almost entire change-although he was a full blooded Indian, and had been, as he informed me, of an unusually dark complexion, for one of his race. No vestige of the original colour remained, except on the face and arms; of the former, it might have occupied a fourth part, and on the latter, only a small patch was heie and there to be seen. On every other part the skin was remarkably clear and white, very delicate and altogether free from disease. Indeed I do not recollect ever to have seen a skin more delicate than his. At the period abovementioned he was in good health, although more than ninety years of age, and during the summer previous, had laboured daily on his farm. He has been temperate during his whole life, and with one or two exceptions has uniformly enjoyed good health. The change of colour seems, (from his own statement) to have commenced at about the age of 60 , in a small triangular patch near the pit of the stomach, and during a state of convalescence from an attack of acute rheumatism. Other similar spots succeeded on different parts of the body, from which as so many centres the change advanced in every direction. The different functions of the system were carried on with a degree of vigour and regularity altogether uncommon in subjects of advanced age. -To this remark, however, the functions of the skín constituted an exception. He hever perspired sensibly, even in the hottest weather and during hard labour. His skin was extremely tender, being lacerated by the slightest scratch ; invariably blistered by exposure to the sun in hot weather, and remarkably sensible to changes of atmospheric temperature. I have not seen him since the year 1816 , but have been credibly informed that be continued to loose his original colour until the time of his death, which happened in the year 1818 , from a pulmonary complaint. Within a few months 1 have seen another instance of a similar nature in a female of the same tribe, between fifty and sixty years of age. In this case the change was a partial one, being confined wholly to the arms, it followed an attack of pneumonic inflammation. These are the only instances of this singular occurrence among the aboriginals of our country which 
liave ever come to my knowledge, although there are several tribes in this section of the country. I do not know that an Albino has ever been produced among them. In the two cases here given, the change brgan at an advanced period of life, and immediately subsequent to inflammatory diseases. How far the previous condition of the system might have contributed to the production of such an event, or whether it had any influence at all, I leave for others to decide.

Clinton, Oneida, County, New-York, May 21, 1821.

[Comurunicated for the Nerr-England Journal of Medicine, \&c.]

\section{Messrs. Editors,}

TN the last number of your useful Journal, you have published a communication from me, of the very striking and immediate salutary effect of Arscric in a case of most obstinate and long protracted Syphilis. I have thought it might be useful, to send you a case of a different discase, in which this Sampson of the Materia Medica displayed its astonishing power to artest morbid and noxious associations in the human system, and by its agency, to restore that uniform, equable action, on which health so much depends. We are in the possession of no other medicine, en- , dued with so much power to stimulate every moving and living fibre in the system, and to render such stimulation permanent, and which, at the same time, can be so readily mauaged and controlled, as Arsenic ; for in an experienced laand, with proper care and watchfulness, this medicine leaves no noxious effects behind. Nor does it ever, like Mercury, when the system submits to its influence, produce such unmanageable effects and distressing symptoms, or such debilitating discharges.

When we administer Arsenic, we have sufficient warning and timely notice, by certain marks and symptoms; which cannot be misunderstood, that will adinonish us, as we approach the boundaries of safety, to withdraw, or lessen the cause of these appear. ances. Or, when we find that our dose has been imprudently or accidentally increased so far, that a continuance of the medicine in any quantity would be unsafe, by a dose of salts and the abslaining one or two days from its use, the effect, and every ves. tige of the overdose will disappear.

In the use of Mercury it is otherwise; for how frequently do we find, that in its most careful and guarded administration. cases of distressing salivation suddenly occur, which bid defi- 